\title{
Study on the Construction of Teachers in the Background of Charge on Postgraduate Education
}

\author{
Minhua $\mathrm{Xu}^{1}$, Zhiying Wang ${ }^{2}$ \\ 12 Jilin Agricultural University, Changchun 130118, china
}

\section{Keywords: Postgraduates; Teachers; Agriculture; Charge}

\begin{abstract}
As the system of charge on postgraduate education comes into effect, some new problems will certainly occur, which may influence the quality of cultivating postgraduates. For agricultural universities, they are short of excellent students, so it is necessary to further strengthen the construction of instructors, teachers and tutors. Regarding the working mode of postgraduate instructors and their business examination system, course team construction, course undertaking ways, postgraduate cultivation process management, and scientific research progress sharing plans, specific reform measures are put forward in this paper, so as to improve postgraduate education in the future and gradually meet the quality requirements of cultivating agriculture sciences postgraduates in the background of the charge system.
\end{abstract}

\section{Introduction}

As a key part of higher education, postgraduate education is on the very top of the national education system. It is not only a critical approach to cultivate high-level innovative talents, but also an important source to carry out cutting-edge technological innovation and fundamental researches. In 2014, over 630,000 full-time postgraduates were recruited in China, the number of which ranked among the top list worldwide. According to documents like "Opinions on Improving the Postgraduate Education Input Mechanism by the Ministry of Finance, National Development and Reform Commission, and Ministry of Education" (Cai Jiao [2013] No.19), the charge system for postgraduate education would come into effect since the autumn semester in 2014. The purpose is to expand fund input channels for postgraduate cultivation, increase the input in postgraduate education, and fully invigorate the vitality of postgraduate education. As a result, the mechanical reform of postgraduate cultivation can be deepened and the quality of postgraduate cultivation can be enhanced comprehensively.

Since the postgraduate education shifted from "being at public expense" to "being at students' own expense", the economic pressure of postgraduates has been increased, and the conflict between postgraduates and their tutors may gradually be intensified as well. In agricultural universities, especially some local ones with the lack of popular majors that have positive employment prospect, plus the influence of long-cycle field tests, high labor strength, and boring research contents, the independent study and innovation competence of postgraduates are relatively insufficient with weak competition in groups. With the introduction of the charge system, the quantity and quality of postgraduates will decrease at first. Moreover, non-popular majors may attract fewer students. Therefore, when facing new problems of postgraduate education and discipline characteristics of agricultural universities, the incentive function of postgraduate award system should be realized despite of the charge system, thus fully motivating the learning and enthusiasm of scientific study by postgraduates. The construction of postgraduate supervisors, teachers, and tutors should further be enhanced, thereby gradually improving the cultivation quality and increasing students' competition competence.

\section{Strengthen the Construction of Postgraduate Instructors}

Postgraduate instructors refer to teachers engaging in the mental and political education for postgraduates under the leadership of the Chinese Communist Party. As organizers and guiders carrying out political and mental education as well as daily management work in institutions of higher 
learning, they are responsible for organizing the moral education, mental education, League construction, Party construction, and daily normalization management work of postgraduates. As the backbone force of mental and political education for postgraduates and the basic-level workers, postgraduate instructors are political "leaders" for postgraduates, "close friends" of them in life, "co-workers" of them in academic study, and "assistants" of competent departments as well.

Currently, institutions of higher learning are paying high attention to the construction of undergraduate instructors, the role positioning of which is clear with improved promotion systems and high working passion of instructors. However, in some universities, especially local ones starting postgraduate education late, their role positioning of postgraduate instructors is still unclear, and the postgraduate instructors' duties are confusing. Although specific positioning has been carried out for postgraduate instructors by some universities, the promotion examination indexes for postgraduate instructors are the same as that for undergraduate instructors. For the purpose of personal progress and development, postgraduate instructors undertake similar with to undergraduates along with consistent requirements, and they compete with undergraduates in appraisal. It seems such indexes have managed to examine the working ability of postgraduate instructors, they actually play a role in deviating the correct direction of postgraduate training and quality improvement.

To further improve the postgraduate cultivation quality, relevant units should further strengthen the construction of postgraduate instructors. Specific measures are reflected in:

Perfect Selection, and Intensify the Training Mechanism. In recent years, with the penetration of construction of a clean government and the improvement of the recruitment system in institutes of higher learning, employers can select talents on the basis of justice, fairness and equality, thus raising the threshold of postgraduate instructors.

However, many postgraduate instructors are lack of working enthusiasm at work, and their working effect is unsatisfactory. Reasons are analyzed below: Longitudinally, compared to students working in companies, postgraduate instructors have low salary income but high working strength; Horizontally, examination indexes for undergraduate instructors and postgraduate instructors lean towards undergraduate education, and the promotion system is not specific to postgraduate instructors whose source level is higher than their counterpart. As a result, postgraduate instructors tend to work passively and play the role of "assistants" who can basically make response to issues immediately but with a lack of "the sense of responsibility", that is, they fail to prevent the occurrence of some emergencies positively. Hence, it is critical to strengthen the postgraduate instructor training and cultivation work in order to promote the construction of postgraduate instructors. Only by improving the personal quality of postgraduate instructors can it be likely to make them positive and optimistic, thus creating the research atmosphere with the coexistence of cooperation and competition. Agricultural universities should strengthen the agricultural learning and devotion mind by postgraduate instructors with the adherence to the system of training first and working second. The multi-level and multi-form special training system should be established to further broaden their mind and increase their capacity of resolving practical problems.

Be Clear about Positioning, and Perfect the Examination and Evaluation System. First of all, it should be noted that postgraduate instructors not only engage in education management but also in educational teaching. They are cadres and teachers. From the perspective of work positioning, they should especially be distinguished from postgraduate secretaries and got rid of routine trivial business. In this way, postgraduate instructors can spend more energy on the mental and political teaching of students.

In addition, unified management for postgraduate and undergraduate instructors is conducted in many universities with the adoption of the same examination indexes and promotion systems, which, however, is not conductive to the personal development of postgraduate instructors. In fact, the two can be managed by the same department, but their work performance shall not be measured with the same standard. Therefore, competent departments should realize the special characteristics of postgraduate instructors and establish a set of rather independent performance examination indexes. Moreover, the formulation of examination indexes should facilitate the creation of competitive atmosphere and individualized training of postgraduates. Through the joint efforts made by 
postgraduate instructors, tutors, teachers and the school, the postgraduate training quality will be improved.

Improve Treatment, and Stabilize the Team. Currently, many postgraduate instructors are trying every means to work in the administrative department of schools. Considering postgraduate instructors are full of energy with high personal level, the administrative department is usually willing to accept them, thus leading to the huge change of the postgraduate instructor team. Postgraduate instructors may be transferred to other positions when they have just got experience in the previous job. Thus, schools should provider certain policy inclination in terms of welfares, treatment, and title promotion. For instance, for postgraduate instructors who have no wish of getting promotion and who have worked for a long time, they can be allowed to be involved in the title promotion of the teacher series with less rigorous requirements, thereby stabilizing the team.

Reform the Work Mode. First of all, due to the difference in educational objects, especially since the charge system comes into effect, postgraduates bear huger economic pressure, so, unlike undergraduate instructors, postgraduate instructors do not have to persuade students to be devoted in academic learning. Secondly, the contact time between postgraduates and tutors is much more than that in the undergraduate period, and the dependence of students on instructors has been lowered. Thirdly, the team awareness of postgraduates is stronger, because many tasks assigned by the tutor have to be done by groups. Due to these factors, compared to undergraduate instructors, each postgraduate instructor has to manage much more students, most of whom are allocated by grades by the school. Because the grade of students is the same, and the same task is conducted in the same period, the work of postgraduate instructors is more centralized.

Of course, such work mode is beneficial, but the major problem is that it has neglected the problem of insufficient contact between instructors and postgraduate tutors. Therefore, it is suggested that each postgraduate instructor can be responsible for all postgraduates of three grades with different major background. In this way, postgraduate instructors can have better understanding about majors and contact more with postgraduate tutors. Thus, targeted cultivation plans can be made and corresponding administration measures can be designed for postgraduates in accordance with the major features, team specialties, and tutor characteristics, so as to prompt the individualized development of students. Meanwhile, postgraduate instructors can carry out in-depth scientific research work of students and actually become "co-workers" of students academically.

\section{Strengthen the Construction of Teachers}

According to the fifth article of the "Regulation of Academic Degrees of People's Republic of China", postgraduates mainly realize the goal of "commanding solid basic theories and systematic expertise of the discipline" through the course learning, while teachers of the basic courses and specialized courses are dominators of the process. Therefore, teachers are playing an important role in the professional basic knowledge commanding and subsequent scientific research of postgraduates.

The construction of teachers is mainly reflected in the teacher bring-in and teaching process management.

Teacher Bring-In and Re-Education System Construction. Currently, universities are working on strengthening the construction of the teachers, further optimizing the age structure, educational level structure and degree proportion structure of the teacher team, and cultivating and introducing top-notch talents or academic leaders with significance influence. The above thought and method have been carried out by many schools, and many successful cases can be seen. Due to the limitation of regions, economy, working environment, and children's education environment, local institutions in mainland areas still require gradual improvement. With the rapid economic development and continuous reform penetration, the team of college teachers will certainly be expanded to gradually meet the needs of the talent strategy at present.

Teaching Process Management. Affected by some objective factors, postgraduate course teaching is attached with less importance than undergraduate teaching, especially in classes taught by deans taking part-time job in the administration department or some big professors, classes are often suspended because the teacher is out for a meeting or on a business trip, so the teaching quality is hard 
to be guaranteed. According to requirements of relevant regulations, those teachers who cannot guarantee the teaching quality can be punished in order to control the teaching process. However, much absence is caused for public affairs, so no good solution has been found yet. The most effective way to resolve this issue is to strengthen the course team construction and reform the course undertaking mode. A course may be taught by several teachers at the same time, so that the class sequence can be adjusted by teachers, no class suspension will occur any more, and the teaching quantity can be guaranteed. On the other hand, if one course is undertaken by several teachers at the same time, the class teaching hours of each teacher will be reduced, so that they will be more devoted in teaching and make the teaching quality improved. Another advantage of setting the course in this way is that the teaching and learning hours of the course can be significantly reduced and that students can finish one-year's course learning in only one semester. In this way, the field survey can be conducted in the second semester of the first grade. For regions like north which is cold all year round, there are 2 planting circulations for three-year-program postgraduates in agricultural universities, and the conclusion drawn from the field survey can be more reliable. Of course, more teachers shall be available for the realization of such reform, so schools can consider increasing the number of teachers appropriately.

In terms of the examination mode, the form of using summary papers for the final examination should be rejected resolutely, so as to avoid the randomness of examinations. The solution should be in this way: For public basic courses, the closed-book exam score should be higher than $80 \%$, and the closed-book exam for specialized courses and professional basic courses should be higher than 50\%. In addition to closed-book exam scores, the total score of each course should also contain 2-3 items of the assignment completion at ordinary times, class discussion, experiment skills, paper writing, and information acquisition and handling in scientific researches, thus making the overall course score better reflect the course command ability of students and fulling mobilizing students' subjective initiative. Furthermore, it can help to make assessment in the student subsidies for postgraduates and coordinate with the charge system for postgraduates.

\section{Strengthen the Construction of Tutors}

The biggest difference between postgraduate education and other levels of education is "research" whose core is "innovation". Therefore, the core target of postgraduate education is the cultivation of students' innovation ability. The realization of that requires students to have rational knowledge structure and solid expertise. It is also closely related to the guidance by tutors. So, requirements for tutors in postgraduate cultivation are higher, because tutors need to have noble morality, solid theoretical foundation, profound knowledge, and unique opinions in scientific researches.

To enable tutors to meet the requirements for cultivating postgraduates' innovation ability under the new situation, it is needed to re-construct the tutor selection index system and strengthen the management of the guidance process.

The Tutor Selection Index System. The construction of the tutor selection index system should include the moral quality, physical and psychological quality, knowledge quality, innovation quality, scientific research level, guiding level, information level and management level of tutors, and it should cover the occupational morality, physical conditions, and performance conditions of tutors. Regarding the tutor selection, rather well-grounded rules and systems have been formulated by postgraduate cultivation units. Nonetheless, in face of the reform of the charge system on postgraduates, the economic pressure of postgraduates is larger, so they need more help from tutors in life. For this, tutors have to have enough scientific research funds for support. In addition, to make sure that tutors can spend sufficient energy in strengthening the guidance for postgraduates, the number of students guided by each tutor should be restricted by cultivation units. Of course, the establishment of these index systems needs to be in line with the actual situation of corresponding units, including the teacher-student ratio, tutor fund sources and quantity, and hardware cultivation conditions.

Cultivation Process Management. First, the duty of tutors should be clarified, and the all-around guidance by tutors for postgraduates' scientific research work should be normalized, including the 
normative education of experimental operation, training for use methods of large instruments, field survey design and management, statistical analysis of data, and paper writing.

Second, through the laboratory safety education and examination, access system installation in laboratories, postgraduates' attendance check, original record filing and other measures, it is to strengthen the scientific research management towards postgraduates by tutors.

Third, via the course learning guidance, project setting, mid-term examination, scientific research paper publishing, degree paper writing and other cultivation process management, it is to construct a high-quality cultivation system for postgraduates majoring in agriculture in northern universities. Based on the system construction, the management of postgraduates' tutors can be strengthened, and a qualified team of tutors can be constructed.

Young Tutors Should Be Encouraged to Exercise in the First Line of Agriculture Production. From the perspective of workload check, achievement recognition, and title evaluation, schools should encourage young tutors and young teachers who will become tutors soon to make full use of their after-class time and be involved in the first line of agriculture production in combination with their own scientific researches. For this, we should learn from the experience of the "scientific and technological courtyard" from Resource and Environment School of China Agricultural University and strengthen the cultivation of practical agriculture production by young teachers.

Improve the Scientific Research Progress Sharing Plan. Feasible implementation rules should be made by schools specific to the ranking and scholarship allocation of scientific research achievements like paper publishing, patent authorization and scientific research projects with the involvement of postgraduates. Tutors should be required to allow postgraduates to be involved in the bonus distribution, so as to encourage them to carry out scientific researches.

\section{Conclusions}

It is the premise and guarantee of improving the professional postgraduate education quality by having a faculty team with agriculture background, rich teaching experience, exquisite practical skills, and rational structure. Through the recent few years' exploration and practice, the production-learning-research cooperation platform has been constructed in the agriculture field, which has strengthened the establishment of postgraduates' agriculture background while enhancing tutors' professional ability. The proportion of postgraduates directly involving in research projects accounts for $70.3 \%$, and that of postgraduate tutors with "two teaching titles" take up more than $30 \%$, which has effectively satisfied the demands for "skillful and compound" talents by enterprises and units.

\section{References}

[1] Overall Implementation of Charge on Postgraduate Education [N]. Guangming Daily, 2013-3-4 (3).

[2] Li Tao. Study on the Postgraduate Instructor Competence Based on the KPI Mode [J]. Educational Theories and Practice, 2014, 34 (15): 30-32.

[3] Zhou Wenyong, Cai Sanfa, You Jianxin. Discussion on the Quality Management in Scientific Researches by College Postgraduates [J]. Degree and Postgraduate Education, 2006, (4): 57-59.

[4] Zhang Ynag. Status and Analysis of Academic Postgraduates from Agricultural Universities Participating in Project Researches of Tutors [J]. Chinese Agriculture Education, 2014, (4): 51-57. 